Fixed Point Theory, 23(2022), No. 1, 211-218

DOI: $10.24193 /$ fpt-ro.2022.1.13

http://www.math.ubbcluj.ro/ nodeacj/sfptcj.html

\title{
A NOTE ON THE RATE OF CONVERGENCE OF VISCOSITY ITERATIONS
}

\author{
VITTORIO COLAO \\ Department of Mathematics and Computer Science, \\ University of Calabria, Italy \\ E-mail: vittorio.colao@unical.it
}

\begin{abstract}
In [6], Moudafi introduced the so-called viscosity iterative method to approximate a fixed point of a nonexpansive mapping and proved the strong convergence of the generated sequence. Since then, several authors extended the convergence result in different settings and for mappings satisfying general metric conditions. Anyway, to the best of our knowledge and beside numerical simulations, little is known about the speed of convergence of the method itself. In this paper, we propose a step in this direction by giving an estimate for the rate of convergence of viscosity sequences generated by quasi-nonexpansive mappings in the setting of $q$-uniformly smooth Banach spaces.
\end{abstract}

Key Words and Phrases: Nonexpansive mapping, contractive mapping, iterative method, uniform smooth Banach space, duality map.

2020 Mathematics Subject Classification: 47J05, 47J25, 47J26, 47H09, 47H10.

\section{REFERENCES}

[1] J. Baillon, R.E. Bruck, The rate of asymptotic regularity is $O\left(\frac{1}{\sqrt{n}}\right)$, Theory and Applications of Nonlinear Operators of Accretive and Monotone Type, (1996), 51-81.

[2] V. Berinde, Iterative Approximation of Fixed Points, vol. 1912, Springer, 2007.

[3] R.E. Bruck, A simple proof that the rate of asymptotic regularity of $\frac{I+T}{2}$ is $O\left(\frac{1}{\sqrt{n}}\right)$, Recent Advances on Metric Fixed Point Theory (Seville, 1995), 11-18, Ciencias, 48, Univ. Sevilla, Seville, 1996.

[4] C. Chidume, Geometric Properties of Banach Spaces and Nonlinear Iterations, vol. 1965, Springer, 2009.

[5] R. Cominetti, J.A. Soto, J. Vaisman, On the rate of convergence of Krasnoselskii-Mann iterations and their connection with sums of Bernoulli' s, Israel Journal of Mathematics, 199(2014), no. 2 .

[6] A. Moudafi, Viscosity approximation methods for fixed-points problems, Journal of Mathematical Analysis and Applications, 241(2000), no. 1, 46-55.

[7] G. Pisier, Martingales with values in uniformly convex spaces, Israel Journal of Mathematics, 20(1975), no. 3-4, 326-350.

[8] B.T. Polyak, Introduction to Optimization, Optimization Software, Publication Division, New York, 1987.

[9] S.A. Rakov, Uniformly smooth renormings of uniformly convex Banach spaces, Journal of Soviet Mathematics, 31(1975), no. 1, 2713-2721. 
[10] T. Suzuki, A sufficient and necessary condition for Halpern-type strong convergence to fixed points of nonexpansive mappings, Proc. American Mathematical Society, 135(2007), no. 1, 99106.

[11] T. Suzuki, Reich's problem concerning Halpern's convergence, Archiv der Mathematik, 92(2009), no. 6, 602-613.

[12] X. Tao, H.K. Xu, An iterative method for a nonlinear equation governed by accretive nonexpansive mappings in Banach spaces, Journal of Nonlinear and Convex Analysis, (to appear).

[13] H.K. Xu, Inequalities in Banach spaces with applications, Nonlinear Analysis: Theory, Methods \& Applications, 16(1991), no. 12, 1127-1138.

[14] H.K. Xu, Iterative algorithms for nonlinear operators, J. London Mathematical Society, 66(2002), no. 1, 240-256.

[15] H.K. Xu, An iterative approach to quadratic optimization, J. Optimization Theory and Applications, 116(2003), no. 3, 659-678.

[16] H.K. Xu, Viscosity approximation methods for nonexpansive mappings, J. Mathematical Analysis and Applications, 298(2004), no. 1, 279-291.

Received: October 22, 2020; Accepted: December 7, 2020. 
